How to cite: Wall, Erika \& Olofsson, Anna. (2008). Young people making sense of risk: How

meanings of risk are materialized within the social context of every-day life. Young, 16 (4) 431-448.

Published by:

\title{
Young
}

doi: 10.1177/110330880801600405

\section{Young People Making Sense of Risk}

An empirical and theoretical development of a new concept

\author{
Erika Wall and Anna Olofsson \\ Department of Social Sciences \\ Mid Sweden University
}

\begin{abstract}
By launching the term 'sense-making', our intention is to deepen the understanding of young people and risk. Seven focus group interviews were made in 2004/05, including three reference interviews with adults: four in an urban area (Greater Stockholm) and three in a rural area (the county of Jämtland). The results indicate that sense-making of risk is a fruitful way of capturing hidden heterogeneity among young people with similar risk perceptions. Young people in rural areas tend to make sense of risk according to $u s$-here, a collectivistic and embedded view of risk, while young people in urban areas have an individualistic and disembedded view, expressed according to me-there or me-where I am. This can be interpreted as such that young people's sense-making of risk is based in different modernities, entangled with each other through e.g. global mass communication systems.
\end{abstract}

\section{Introduction}

This article focuses on young people living in urban and rural areas, and how they make sense of risk. Research on young people and risk is often associated with risk behaviour and at-risk youth, i.e., it concerns drinking and drug habits, crime, sexual behaviour and related diseases. In these types of studies, risk perceptions are used as a measurement of exposure and individual choice in relation to risk behaviour. This article employs a different perspective on young people and risk. The aim is to reach a deeper understanding of young people's sensemaking of risk by including the role of the place where they live. 
How to cite: Wall, Erika \& Olofsson, Anna. (2008). Young people making sense of risk: How meanings of risk are materialized within the social context of every-day life. Young, 16 (4) 431-448.

Contrary to risk perception studies (cf. Slovic et al., 1977, Slovic et al., 1980), which focus on the individual's cognitive processes in evaluating risks, we apply a sociologically defined view of risk (cf. Lupton \& Tulloch, 2001, Lupton \& Tulloch, 2002, Tulloch \& Lupton, 2001) ${ }^{1}$. The term we want to launch, 'sense-making of risk', captures how risk is put in the everyday-life context of young people. The individual's understanding of risk is not only an individual construct but also influenced by social relations and general beliefs about the world and life (cf. Weick, 1995). It is in the interaction with other people that norms and understandings are created, from which the individual then makes sense of his or her surrounding world, not least risks. Compared to other concepts describing social processes and collective influences, i.e. 'gemeinschaft', socialisation or concepts relating to structural functions, sense-making of risk has several advantages: By studying the sense-making of risk we want to emphasise these influences, since we believe that sense-making of risk is more important for young people's risk behaviour than individual risk perceptions.

Risks emerge not only in the physical world but also in people's images and perceptions of the surrounding world (Beck, 1992, Giddens, 1990). Globalisation and individualisation are two other trends that influence people's understanding of risk. Not only are risks such as global warming and pandemics perceived as threatening, but the way in which we travel and interact internationally makes us vulnerable to risks that were previously limited to people in particular places. The tsunami in Southeast Asia is one such example, where not only the local population was stricken but also tourists from other parts of the world. The second trend, towards individualisation and de-traditionalisation, means that the individual is expected to handle issues of risk and danger to a greater extent than previously. The question is, however, whether these trends indicate a universal change comparable to the development from feudal

\footnotetext{
${ }^{1}$ Lupton and Tulloch apply a sociocultural perspective of risk understanding, where individual identity is more emphasised and the individuals' construction of risk is seen as based in a sociocultural context (Lupton, 2001, Lupton \& Tulloch 2002, Tulloch \& Lupton, 2001). We use 'understanding of risk' as an umbrella term where 'risk perception' and 'sense-making of risk' are subordinate categories: risk perception representing the individual mainly cognitive aspect of risk understanding, and sense-making representing the socially embedded aspect of risk understanding.
} 
How to cite: Wall, Erika \& Olofsson, Anna. (2008). Young people making sense of risk: How

meanings of risk are materialized within the social context of every-day life. Young, 16 (4) 431-448.

to industrialised society, or if the two trends rather can be understood as parallel processes (cf. Therborn, 2003). There is not necessarily a relationship between globalisation of communication, economy and risks on the one hand, and individualisation and detraditionalisation on the other. These concepts have to be put into context, particularly a local context, to be further examined. According to our view, earlier studies tend to focus on urban areas, particularly cosmopolitan cities, while rural areas have been neglected or only used as a contrasting example.

Social changes influence not least the lives of young people. In the absence of traditional social structures and intensified individualist values, the social world becomes regarded as unpredictable, risky and a challenge for the individual. As Furlong and Cartmel (1997b) conclude in their study of young people living in the UK: 'Blind to the existence of powerful chains of interdependency, young people frequently attempt to resolve collective problems through individual action and hold themselves responsible for their inevitable failure.'. Their study of young people, made in the mid-90s, empirically tests the assumptions behind Ulrich Beck's and Anthony Giddens' theories of late modernity. As we can see, it confirms the trend of individualisation and the changing role of risk and uncertainty, but what is more interesting, it challenges the role of globalisation and individual reflexivity in the life of young people, and specifically Giddens' argument of the declining significance of where people live, or 'space', in times of global mass communications systems. Furlong and Cartmel (1997a) argue that mediated experiences rather distort people's views of reality by showing possibilities and opportunities that are unavailable in a specific local place. Contrary to Giddens' argument of space, local social and physical structures restrain the individual's opportunities and options. Inspired by Norbert Elias, Furlong and Cartmel conclude that young people see themselves as independent individuals responsible for their own life 
How to cite: Wall, Erika \& Olofsson, Anna. (2008). Young people making sense of risk: How

meanings of risk are materialized within the social context of every-day life. Young, 16 (4) 431-448.

chances, but are in fact part of chains of mutual dependencies tied to the local context of everyday life.

Inspired by Furlong and Cartmel (1997b), we would like to refer to some of the questions which they focused on, particularly the role of where young people live in relation to risk, globalisation and individualisation. However, we will add the concept of sense-making to capture the social context and thereby reach a deeper understanding. Young people, their values and behaviour, are often used as an indicator of changing conditions in society at large. The question is whether the place where people live is also an important factor when it comes to their sense-making of the world.

\section{Theoretical framework}

Research about young people and their transition into adulthood often focuses on work, identity, consumption and at-risk behaviour. However, during the last decade youth research has begun to focus on the consequences for young people growing up in a late modern society (Denscombe, 2001, Green et al., 2000, Lawy, 2002, Furlong \& Cartmel, 1997b). ${ }^{2}$ Western societies have moved from a feudal to an industrialised society, often described as a development from a traditional to a modern society. However, authors such as Beck and Giddens argue that the modern society described by e.g. Tönnies, Durkheim and Weber is beginning to dissolve and is being replaced by a new stage of modernity: late modernity, characterised by globalisation, risks and individualisation. Risks produced within the industrialised society are seen by both Beck and Giddens as an important change factor in the transition from modernity to late modernity, or in Beck's words: 'risk society' (Beck, 1987, cf. Giddens, 1990, Beck, 1992, Beck, 2002). Both Beck and Giddens argue that modern society has modern risks, i.e. man-made, compared with the pre-modern time, which also had its risks, seen as driven by nature or an act of God (Beck, 1992, Giddens, 1990, Giddens,

\footnotetext{
${ }^{2}$ For an overview of studies about young people in risk society, see Cieslik \& Pollock (2002).
} 
How to cite: Wall, Erika \& Olofsson, Anna. (2008). Young people making sense of risk: How

meanings of risk are materialized within the social context of every-day life. Young, 16 (4) 431-448.

2002). Neither Beck nor Giddens claim that risks increase, rather that they strike globally and the consequences become more fatal (Beck et al., 1994). Critics like Turner (1994) question whether the occurrence of for example plagues in earlier centuries may have had the same characteristics as modern risks.

An alternative way of conceptualising late modernity is to emphasise the dimension of space rather than time by adopting a non-linear view. This means allowing 'multiple modernities' (Therborn, 2003:294). In other words, not all people in a population hold the same values and norms; some might be more traditional with collective values, while others are more individualised and 'late modern'. These parallel modernities are not separated, but rather intertwined, or entangled as Therborn (2003) expresses it. One example of people who might live in entangled modernities in Sweden today is children of immigrants who might combine their new country's traditions and life at school, with the traditions and lifestyle of their native country at home with their parents.

It is not only risks that are globalised in late modernity; on the contrary, Giddens (1990) suggests that both time and space are lifted out of the local context, or are 'disembedded'. Social relations, economic transactions and information are reconstructed in a broader context, crossing time and geographical boundaries.

Place, or locality, is the geographically defined part of space and can be described as a named and unique spot in the universe (Gieryn, 2000). Place, as in 'where you live', is by many seen as less important in times of globalisation. This aspect is not least common in youth research, and growing up is sometimes described as a collective experience, shared by young people around the world (Pollock, 1997). At the same time, the role of local and regional contexts is emphasised when the power of the nation state declines (Beck, 2003, Beck, 2004, Giddens, 1991). What we have here is two perspectives: one where place has become relative (Giddens, 1991, Giddens, 2002) and the other where place still matters as an 
How to cite: Wall, Erika \& Olofsson, Anna. (2008). Young people making sense of risk: How

meanings of risk are materialized within the social context of every-day life. Young, 16 (4) 431-448.

important everyday-life context (Beck, 2004, cf. Gieryn, Lindstrom). These two views of place conflict in the study of urban areas, particularly cosmopolitan cities, where access to technological devices disembeds time and space, and thereby makes experiences of issues of global concern possible (cf. 'glocalisation'). In studies of this type, place as in 'where you live' often equals big cities, which enables the individual to 'disconnect' from the particular locality and become part of a globalised world. What seem to be forgotten, or at least overlooked, are rural areas, where access to disembedding technologies can be limited and where social bonds are strong. Urban areas tend to be the 'normal state', also in youth studies, while rural areas are neglected or used as a comparison (see e.g. Pollock, 1997). Even though many people in the West today live in urban areas, a relatively large group of people still live in small towns and in the country, and these rural areas are part of the modernisation process just as big cities are. Earlier research concerning young people in rural areas and risk is limited, and the existing studies focus on conditions of growing up and marginalisation rather than the sense-making of risk in late modernity (see e.g. Heggen, 2000, Morse Dunkley, 2004, Nairn et al., 2003).

The changed role of place is accompanied by individualisation during late modernity. According to Beck, a kind of 'false' individualisation emerged during the industrial society (Beck et al., 2003); individuals were seen as free and equal but their freedom was shaped by pre-modern structures determined by birth, e.g. class and gender. During late modernity, the individualisation process is intensified by the development of the welfare state and a detachment from pre-modern social structures and traditions (Beck, 1992, Beck \& BeckGernshiem, 2001, Giddens, 1991, Giddens, 1994). Instead of being dependent on collective social forms, the individual becomes dependent on e.g., social policy, economic markets and fashion, to construct his or her personal biography (Giddens, 1991, Green et al., 2000). The self becomes an ongoing project where nothing is fixed for more than a limited period of 
How to cite: Wall, Erika \& Olofsson, Anna. (2008). Young people making sense of risk: How

meanings of risk are materialized within the social context of every-day life. Young, 16 (4) 431-448.

time; studies, work, place of residence, relationships with friends and family and even personality and body shape become subject to questioning and change. Globalised communication, mainly through mass media, gives a smorgasbord of possible life biographies and choices for the individual, or at least it gives such an impression (cf. Furlong \& Cartmel, 1997b).

To sum up, globalisation and individualisation are central concepts, together with risk, in modernisation theory, but the focus is almost exclusively on cosmopolitan cities, while rural areas and their inhabitants, e.g. young people, are neglected. By including the social aspect of risk understanding, i.e., sense-making, we can go beyond the mere given and better comprehend the situation of young people living in different places today.

\section{Method}

This study is based on an empirical material composed of focus group interviews made in urban and rural areas of Sweden in 2004 and 2005. Seven interviews were made in all: four with young people, the main object of the study, and three with adults, as reference interviews. This method is suitable when dialogue and social interaction is central (Morgan, 1996, Wibeck, 2002), which is important when studying sense-making of risk. The group interviews make it possible to study how people discuss and relate to risk in social contexts.

The urban-rural perspective is central in this study, and therefore half of the groups were made in rural areas in the county of Jämtland in the north-west of Sweden, and half in Greater Stockholm, the only city with more than a million inhabitants in Sweden. The rural area is characterised by sparse population and long distances to towns and cities. The living conditions differ significantly from other areas in Sweden, and also from central Europe where such sparsely populated areas are rare. The county of Jämtland is inhabited by 113,000 people in an area of 34,000 square kilometres, an area comparable to Belgium (30,500 square kilometres) with 10.4 million inhabitants. Living in an area like this, means that things taken 
How to cite: Wall, Erika \& Olofsson, Anna. (2008). Young people making sense of risk: How

meanings of risk are materialized within the social context of every-day life. Young, 16 (4) 431-448.

for granted by people in urban areas, such as easy access to communication as well as health care and help in case of emergencies, is not always available.

The main criterion in choosing groups, apart from age, was the urban-rural dimension. Gender was also used as a grouping criterion, but only to ensure an open communication. Two interviews, one with boys and one with girls, were made at two different uppersecondary schools in Stockholm ${ }^{3}$, and two with students from an upper-secondary school in the small community of Strömsund, Jämtland. Four people participated in each interview and all the participants were of the same age: between 17 and 18. Two of the reference interviews with adults were made in Stockholm, and one in the county of Jämtland. ${ }^{4}$

During the interviews the moderator initiated the discussions about risks and an observer handled the recording equipment, took notes and observed the social interaction in the group. The interviews began with an open: 'What comes to mind when you hear the word 'risk'?' After the initial discussion, more specific risks were presented. To inspire the participants, stimuli material was used (Gaskell, 2000). Cards with different kinds of risks, from lifestyle risks and everyday-life risks to societal risks, such as global warming and deteriorating public health, were used to stimulate the discussions. The respondents chose which risks they wanted to discuss, but they were also asked to say something about the risks that they did not talk about spontaneously. All of the interviews, both with young people and adults, followed the same structure, but the stimuli material contained more risks in the interviews with young people than with the adults. No questions about identity or local attachment were asked during the interviews, only questions about risks.

All of the interviews were transcribed and analysed using qualitative content analysis (Morgan, 1996). The texts were read and reread in search of themes and sub-themes. The first

\footnotetext{
${ }^{3}$ The headmaster did not give us permission to do more than one interview at each school, which is the reason for doing the interviews at two different schools.

${ }^{4}$ Two interviews were made with people living in Greater Stockholm: one with men $(n=3)$ and one with women $(n=4)$, all aged between 25 and 45. The interview in Jämtland was composed of two men and two women, all aged between 25 and 55 .
} 
How to cite: Wall, Erika \& Olofsson, Anna. (2008). Young people making sense of risk: How

meanings of risk are materialized within the social context of every-day life. Young, 16 (4) 431-448.

reading was open and focused both on the way the participants interacted before and during the interviews, and how they discussed risks. The second reading was guided by the theoretical framework and more particularly the concepts of place and individualisation. In this analysis, new themes were found; following this a third and last reading of the material was made. The interviews with young people were analysed separately from the interviews with adults. The latter material was used to compare with the results from the interviews with the young people; i.e., themes and sub-themes found in the material about young people were searched for in the interviews with adults and no separate analysis was made using this material.

\section{Results and analysis}

The aim of the study is to investigate how young people make sense of risk and whether the place where they live plays a role in this respect. Sense-making is the socially defined view of risk, and it is therefore of interest to include the way the interviewed girls and boys behaved during the interview. We therefore begin with a short description of the settings of the four interviews with young people, after which similarities and differences in risk perceptions are presented, followed by the main results: how the interviewees make sense of risk. In the last section the reference interviews are included.

\section{Settings}

The headmaster of the school introduced both the groups of young people living in rural areas. In both these groups the students were nice to each other and the discussions were characterised by cooperation: during the interviews the participants acknowledged each other and agreed with what had been said earlier in the discussions. The boys were quite relaxed, but they still needed the moderator's help to stimulate their discussions. They gave short answers and mumbled rather than spoke out loud. This was also the shortest interview. The 
How to cite: Wall, Erika \& Olofsson, Anna. (2008). Young people making sense of risk: How

meanings of risk are materialized within the social context of every-day life. Young, 16 (4) 431-448.

girls shook our hands and introduced themselves when we met them. Then they quietly and discretely took their places around the table. The opening questions, aimed to make an open climate of discussion, were not enough and the discussion was not self-generating until the stimuli material was introduced. These girls showed responsibility in giving everyone an opportunity to express their views in the discussions.

The interviews with young people from Stockholm were different. Arguments and counterarguments were a natural part of the discussions and the groups seemed to enjoy the discussions even when they got heated. In these groups the individual's performance was important and the kind of cooperation and team play seen in the groups from Jämtland was not present. The boys strolled into the small conference room in the school when we first met them. They were laid-back as they sat down at the table, and appeared to be curious but a bit lazy. After a while they got more involved and interested in the interview. As in the interview with boys in Jämtland, the boys talked less than the girls. The longest and most selfgenerating interview was the one with the girls in Stockholm, who discussed independently and got involved in the subject. When we took our seats in the meeting room, all of the girls were chatting with us, telling us about who they were and describing the school. In this group we were the visitors and the respondents were our hosts. It felt as if these girls were several years older than the girls in Jämtland, but they were all of the same age.

\section{Shared risk perceptions}

In all groups, two kinds of risks were discussed spontaneously: international terrorism and risks related to the conditions of growing up, the latter referring to children growing up without firm values and rules, and lack of respect among young people. There were many more examples of similarities between individual groups but it is not possible to find any patterns related to place of residence. For example, both the girls in rural areas and those in 
How to cite: Wall, Erika \& Olofsson, Anna. (2008). Young people making sense of risk: How

meanings of risk are materialized within the social context of every-day life. Young, 16 (4) 431-448.

Stockholm were worried about health risks and consequences of immigration, risks not discussed by any of the groups of boys. Nor is it possible to find differences between the groups that apply to modernisation theory, i.e., a greater concern for 'modern' risks such as environmental or political risks in the urban group than in the rural group. Our conclusion is therefore that risk perceptions do not necessarily depend on where people live. However, the question is whether there are differences when it comes to the sense-making of risk?

\section{Young people making sense of risk}

In this section we will deepen the analysis and study how young people who live in different places make sense of risk. Our analyses are based on how the groups discuss the risks and in which context they frame their understandings of risks. In the following analyses the reference interviews with adults are included to enable comparisons.

The analyses show that sense-making of risk differs between the rural and urban groups. Two dimensions were found: us-me and here-there-where I am. The rural groups talked about risks from an $u s$-here perspective relating $u s$ to the family, friends and inhabitants of the local community, and here to the local village and the county. The urban groups talked about risk in terms of me-there or me-where I am, that is, from a more individualised perspective. There and where I am, show that risks are not fixed to a certain place but can either be global or vary depending on the individual's relation to specific places. The following sections will present these dimensions of sense-making of risk further, and supplement them with quotations from the interviews.

\section{Us-Me}

Both rural groups have an $u s$-perspective: They talk about themselves as group members and not as individuals, which on the other hand, the participants in the urban groups did. One could say that $I$ and $m e$ were used a lot in the urban groups, and $u s$ and we in the rural groups. 
How to cite: Wall, Erika \& Olofsson, Anna. (2008). Young people making sense of risk: How meanings of risk are materialized within the social context of every-day life. Young, 16 (4) 431-448.

The rural groups of young people relate risk to others; their close relations with other people in the rural community are always present in their discussions of risks. They talked about social responsibility, for example the importance of taking care of people in order to get a safer society. However, both the girls and the boys also tended to differentiate between us and them, the latter being criminals, immigrants and people not belonging to the groups' definition of $u s$. The girls' discussion about risks relating to migration is one example of the $u s$-perspective:

IP 3RG5: I mean, it depends whether you're talking about refugees or if you count those who're adopted too. We've got one in our class who's from Thailand. There are lots from Thailand.

IP 2RG: Who've got to learn Swedish and all that.

IP 3RG: But they have been quite noisy and difficult, haven't they? I mean, quite a lot has happened when they've been out, and everything.

IP 2RG: But that doesn't mean that that they're all like that, does it?

IP 3RG: But we do have people from other countries here.

IP 2RG: Oh God, yes.

Another example of this is the boys' discussion about criminals and the consequences for themselves and their local community: 'Yes, I mean it could be dangerous for society. Criminals - they don't know what's right or wrong. I mean they could just walk in and kill half of the people at Konsum supermarket...' (IP 3RB). The girls also express a responsibility for people in their surrounding society, most of all for children and old people. Personal risks, such as alcoholism, are also related to the group's concern about people they know: '(...) I mean, I think it's so hard. just here in Ström - and you see all the alcoholics sitting on the park benches.(...) I can't help it, I really feel so sorry for them anyway' (IP 3RG). The way the interviewees behaved during the interviews also illustrates the tendency to act more as a team than as independent individuals.

The $u s$-perspective used by young people to make sense of risk is confirmed by the interviews with adults from the same area. In this group the importance of community spirit was just as obvious, and social responsibility was a natural and important part in their

\footnotetext{
${ }^{5}$ The abbreviation is used to identify the interviewee and stands for Interview Person (IP), their number in each focus group (1-4), Rural or Urban (R/U), Boy, Girl, Woman, Man (B/G/W/M).
} 
How to cite: Wall, Erika \& Olofsson, Anna. (2008). Young people making sense of risk: How

meanings of risk are materialized within the social context of every-day life. Young, 16 (4) 431-448.

discussions of risk: 'People keep an eye on each other. Everyone helps each other. If you don't come home, if you're out a bit longer than expected, then... '(IP 1RW).

Young people living in Stockholm have a different point of departure when it comes to how they make sense of risk. Their discussions are characterised by a me-perspective, also confirmed by the interviews with the adults. One example of the me-perspective is the boys' discussion about public health. They do not see deteriorating public health as a serious risk because they themselves are healthy. One says: 'I think that deteriorating public health is semi-important. I can't claim that my health is particularly bad health - I haven't been sick for three years (...)' (IP 3UB). The girls relate risks to themselves in a similar way: 'It feels like I only have the energy to worry about things that really affect me, and then it's not so much of all this. Then it's just really close things like young people's values and how the school works and stuff. But I don't think I go round worrying about population growth in the world, or about economic decline. Maybe it's egoistic and quite limited, but it's what matters to me that worries me' (IP 2UG).

The urban interviewees also point out the individual's responsibility when it comes to avoiding risky situations, a view found both among young people and adults. In the following example we see how the boys associate risks with a personal everyday situation, that of taking a test in school: 'No, but put it this way: You know there's a risk you'll fail this test, so if you've got any kind of brain at all, you'll start studying, won't you? Either you sit down and study and manage a 'pass', or else you just don't give a shit, but at least you knew about the risk' (IP 3UB). The boys' me-perspective is sometimes combined with something like an usperspective, but not in the same way as in the rural groups. Sometimes they view the world as a common collective society where inequality and unfairness should be eradicated, for example when it comes to poverty: '(...) you could say that it's a risk to my ideology. I mean, it doesn't hurt me much, because I'm fine, but I think it's wrong if I'm fine while others 
How to cite: Wall, Erika \& Olofsson, Anna. (2008). Young people making sense of risk: How

meanings of risk are materialized within the social context of every-day life. Young, 16 (4) 431-448.

aren't' (IP 3UB). They have a kind of generalised us, different from the rural groups where the $u s$-perspective is defined by the local community; poverty is seen more as a threat to the individual's ideology than as a risk for a fellow man.

The focus on the individual, clearly shown in the setting of the interviews, is also central in the two interviews with adults living in Stockholm. They discuss risk from a personal point of view, evaluating risks according to how serious they are for them personally rather than for people in general: 'I think about me betting on something and losing. Taking a risk. I suppose it's sort of, as you say, something you don't want. You're committed to something, or do something, so you take a risk. It could be money, like investing in stocks and shares or anything at all. Maybe a house or...' (IP 2UM).

To sum up, we see that people living in rural areas use an $u s$-perspective on risk, whereas people in urban areas use a me-perspective. We have also seen that the boys in Stockholm tend to combine me with 'us in the world'. The following section will further explore differences between the groups concerning here, there and where I am.

\section{Here-There-Where I am}

As we mentioned earlier, people living in rural areas associated and related risk to here, the local village or county; this is quite contrary to the groups from Stockholm, where the boys and women used a global context, and the girls and men did not relate risks to any specific place at all. In the latter groups the participants tended to describe and evaluate risks solely as individual risks, and geographical references were only related to the individual's personal movements. What we did not find among the urban people is a local, or here-perspective.

One example of the here-perspective is the rural girls discussing the Chernobyl accident. They mentioned consequences of the accident in the town of Chernobyl but no other references to other parts of Ukraine, the world or Sweden, were made. For these girls the Chernobyl accident was associated with problems in the local area: 
How to cite: Wall, Erika \& Olofsson, Anna. (2008). Young people making sense of risk: How

meanings of risk are materialized within the social context of every-day life. Young, 16 (4) 431-448.

IP 3RG: But of course there was this Chernobyl accident? I mean, we've talked about it.

IP 2RG: It was almost all over the world, wasn't it?

IP 3RG: And they evacuated there [in Chernobyl] ....and here in Ström. It was the year before we were born and there were hardly any children out-of-doors playing because people were afraid they would get ill. And all the radiation there was in Chernobyl - I don't think anyone lives there anymore.

Another example is the boys' discussion about environmental risks which they relate to the local community and the local environment: 'And all the pollution in the world. It's getting warmer here, there won't be any snow.' (IP 4RB). It is also important for the interviewees to defend the local village and to emphasise what is unique about their local area. What we find is that the physical place where they live, the local context, is important for how young people make sense of risk. They want to go on living in the same place. The interview with adults living in the same area confirms these results. When they talk about risk in general, they relate it to living in a particular rural area and to the everyday life of the village.

This way of making sense of risk is different from the urban groups' sense-making. The boys, and women, from Stockholm have a there-perspective; that is, they relate risks to the situation in Sweden in general, other countries and globally. When the boys talk about terrorism they do not relate it to their home town Stockholm, but to Sweden in a global perspective: '(...) It's like terrorism - if you imagine a gigantic conflict between East and West, then of course in Sweden they would take the US stand, wouldn't they, and then terrorism would be a threat to Sweden as well' (IP 2UB). The women's discussion of risk is also related to a there-perspective. They relate risk to a global context right from the beginning of the interview: 'Yes, but risk to society could mean more than environmental catastrophes, it could be related to wars of course, terror threats, all around the world (---)' (IP 2UW). They then spontaneously discuss more or less all risks with reference to a global perspective and they also show both interest in and knowledge about global issues in their comments on risks. 
How to cite: Wall, Erika \& Olofsson, Anna. (2008). Young people making sense of risk: How

meanings of risk are materialized within the social context of every-day life. Young, 16 (4) 431-448.

In the interviews with girls and men in Stockholm, risk is not related to a local or a global context to the same degree, but to where I am. This means that when the girls discuss risk they put it in various contexts: everyday life in Stockholm city, journeys they have been on or places they have a connection with or not. What is important for them is how the risks are related to them as individuals when they move through 'space'. Risks in other places are not seen as serious, unless they as individuals have a connection with the place in question. This where I am-perspective can be exemplified by the girls' discussion of political extremism, which is not seen as a risk since it only exists in towns they do not visit: '(...) Well, so far I see it in terms of local phenomena that aren't that important, and don't affect me' (IP 2UG). Hence, risks associated with phenomena without personal connection to the interviewees are not seen as serious. They, as individuals, are the reference point in the sense-making of different risks.

The men have a similar way of making sense of risk; for example, they relate terrorism to personal mobility around the world. One of the men was in Spain at the time of the terrorist attack on the Madrid subway, but he did not use this experience to evaluate risks of terror in general, only for him personally: '(...) Wherever you go, you can run into it. I was in Spain when that train blew up. So I mean, wherever you are...' (IP 2UM).

\section{Summary and conclusions}

The results have shown that the interviewees perceived the same risks as 'serious' both to society and to themselves, which implies that risk perceptions are similar or at least independent of where people live. At the same time, the interviewees differ in the way they make sense of risk, i.e., their socially defined view of risk, which is also confirmed by the results from the reference interviews with adults. The dimensions found, us-me and herethere-where I am, used by the interviewees in their sense-making of risk, can be related to the theoretical concepts of late modernity, or 'risk society'. Us-me corresponds to the concepts of 
How to cite: Wall, Erika \& Olofsson, Anna. (2008). Young people making sense of risk: How

meanings of risk are materialized within the social context of every-day life. Young, 16 (4) 431-448.

individualism versus collectivism, and here-there-where $I$ am to embeddedness or disembeddedness. The first pair of concepts describes the extent to which the individual depends on collective social norms, or is 'free' to create for example his or her own lifebiography (cf. Beck, 1992, Beck \& Beck-Gernshiem, 2001, Beck et al., 2003, Giddens, 1991, Giddens, 1994, Green et al., 2000). The second pair of concepts refers to the way in which both time and space are lifted out of the local context (cf. Giddens 1990; 1991; 1994; 2000) and more specifically the extent to which the individual is rooted in a specific locality, or place (cf. Furlong \& Cartmel 1997b). Young people's sense-making of risk can then be said to be based in a combination of individualistic or collectivistic views and embeddedness or disembeddedness.

Figure 1 shows a theoretical model of sense-making of risk. The empirical material, i.e., the different interviewed groups and their sense-making: us-here, us-there and me-there, mewhere I am, is placed according to how it can be understood in terms of collectivismindividualism and embeddedness-disembeddedness.

\section{Insert Figure 1 here}

The results show that young people in rural areas make sense of risk according to us-here, whereas the urban young people use me-there, or me-where I am. Interestingly, the people living in rural areas share an $u s$-here-perspective, indicating a rather uniform way of making sense of risk, also illustrated by the atmosphere in the groups during the interviews. Young people living in rural areas and their sense-making of risk could therefore be said to be embedded in the local village and established through collective norms and structures in the local community.

In Stockholm, on the other hand, all interviewed groups share a me-perspective, but they differ regarding the there-where I am-perspective. The individualised perspective is also illustrated by the argumentation during the interviews. The tendency to adopt an individual 
How to cite: Wall, Erika \& Olofsson, Anna. (2008). Young people making sense of risk: How

meanings of risk are materialized within the social context of every-day life. Young, 16 (4) 431-448.

standpoint is most clearly seen in the interview with the girls who not only express a meperspective but also make sense of risks according to their own position in 'space'. The boys do not relate to a local, or here-perspective either; they put risks in a non-local, or there, perspective. They also sometimes use an $u s$-perspective, but it is not an ' $u s$ in the local community' but 'us in the world' view, combined with a strong self-image. In other words, for young people living in urban areas sense-making of risk is clearly individualised, established through the individual's personal views. These groups' sense-making is not embedded in the specific place where they live but is disembedded, comparable to a cosmopolitan view, in which the place where people live is only part of a globalised world, or in a more fragmented way, where place is only relevant when it is tied to the individual.

This shows that sense-making of risk is particularly complex among people living in an individualistic and disembedded context. This group bases their sense-making on individual preferences and experiences without being bounded by a particular locality. Their way of making sense of risk will therefore be more heterogeneous compared with people living in an embedded and collectivistic context. In the latter case, collective norms guide the individual in his or her socially defined view of risk. These norms are embedded in a particular geographical place, and as a result, people's sense-making of risk becomes more homogeneous.

\section{Discussion}

The results of this study show that sense-making of risk differs between young people living in urban versus rural areas of Sweden, but at the same time, their risk perceptions are fairly similar. This indicates, firstly, that sense-making is an important aspect of people's understanding of risk and that ignoring this aspect might lead to biased results. To really understand young people's attitudes to risk it is necessary to reach deeper than merely to their 
How to cite: Wall, Erika \& Olofsson, Anna. (2008). Young people making sense of risk: How

meanings of risk are materialized within the social context of every-day life. Young, 16 (4) 431-448.

perceptions. Risk perceptions are interesting per se, but they only say something about the risks that are considered dangerous and threatening, not how the individual deals with them or evaluates them. By reaching a deeper understanding we might also be able to better recognise young people's behaviour in crisis situations. Secondly, theoretically sense-making of risk can be related to two pairs of concepts, individualism-collectivism and embeddednessdisembeddedness, found in theories of late modernity. Sense-making of risk is therefore not only an empirical finding, but it also contributes to the theoretical understanding of risk.

Thirdly, the results indicate the importance of not treating young people as a homogenous group; consideration should be given to where they live, particularly the difference between urban and rural areas, in risk studies. Studies of young people in late modernity tend to neglect the role of place of residence, based on an argument that globalisation makes young people's attitudes and preferences more homogenous (Beck, 2000, Beck, 2002, Giddens, 1991, Pollock, 1997). This is an argument challenged by Furlong and Cartmel (1997b) in their study of young people in the UK, and in the same way as Furlong and Cartmel, we have found that place still matters in a globalised world; i.e., the effects of globalisation on young people might be overemphasised. Contrary to the British study, our results also indicate that the process of individualisation might be overemphasised, since young people in rural areas still have rather collective values (cf. Furlong \& Cartmel, 1997b). Young people in rural areas embrace collective values, while young people in Stockholm are more committed to themselves as individuals. The $u s$-perspective found among the boys in Stockholm is more of a reflexive commitment to absent others who are dependent on 'us, as we are on them', than a question of solidarity towards the local community (cf. the otherness of others Beck, 2004). These results are confirmed by the analysis of the reference interviews with adults living in the same areas, indicating that the difference is not limited to young people but remains 
How to cite: Wall, Erika \& Olofsson, Anna. (2008). Young people making sense of risk: How

meanings of risk are materialized within the social context of every-day life. Young, 16 (4) 431-448.

throughout life; in other words, place of residence might be just as important as age. However, this is not to say that risk perceptions are independent of age.

Our conclusion is therefore that the local community and its social relations play an important role in young people's sense-making of risk. The embeddedness and collectivism expressed through coherence, support and a natural sense of community in the rural area, or the Gemeinschaft, is the context for how young people in rural areas use an us-hereperspective in their discussions of risk. While on the other hand, the disembeddedness and individualism in the urban community based on more impersonal and rational relations between individuals, or the Gesellschaft, constitute the milieu of young people's methere/where I am-perspective.

However, the picture is more complicated than just concluding that sense-making of risk among young people can be understood as Gemeinschaft in the country and Gesellschaft in the city, remembering that the kinds of risk that young people worry about are similar in both rural and urban areas. This indicates that particularly young people in rural areas live in a social reality comparable to a Gemeinschaft; but at the same time they live with the urban information and knowledge that is extended to them by mass communication, comparable to the situation in a Gesellschaft (cf. Mellow, 2005:68). Although globalisation has increased the flow of information, young people living in rural areas seem embedded in the context of the place where they live when it comes to sense-making of risk.

This difference can also be interpreted as parallel modernities existing within the same society, entangled with each other through modern communication devices (cf. Therborn, 2003). A reflection that stems from these results is whether living in multiple modernities, as in the case of young people living in rural areas, creates problems for the individual when he or she has to combine strong ties to the local community and a rather individualised and globalised world. What effects does belonging to multiple modernities have on the individual, 
How to cite: Wall, Erika \& Olofsson, Anna. (2008). Young people making sense of risk: How

meanings of risk are materialized within the social context of every-day life. Young, 16 (4) 431-448.

and how is it possible to handle this 'gavotte' (Mellow, 2005) during the sensitive time of growing up?

As we mentioned earlier, there is a tendency to generalise the situation of living in large cosmopolitan cities to the rest of the population, not least on the basis of globalised communication (i.e. mass media and travel). The sense of a globalised Gesellschaft characterising theories of late modernity might in fact be an artefact of researchers' focus on urban areas, with the result that they fail to see alternative modern characteristics of society in more sparsely populated areas. Rural areas that differ from the thesis of e.g. individualisation are instead characterised as being 'behind' or 'backward'. We want to challenge this idea and argue that the possibility of parallel developments in the modernisation process has been overlooked. In other words, individualisation might be strongly related to living in large cities and not only to modernisation per se.

In this study we can see that sense-making of risk among young people in rural areas is related to a local community of coherence and support, alongside the individualism and disembeddedness characterising social interaction in urban areas; these two are concepts are intertwined with many things, one example of which is nationally and internationally communicated risks. However, further research is needed to see whether the concept of sensemaking is applicable, not only in this particular study but also in other contexts such as young people with different social and ethnic backgrounds, gender and nationality.

\section{References}

BECK, U. (1987) The anthropological chock: Chernobyl and the contours of the risk society. Berkley Journal of Sociology, 32, 153-165.

BECK, U. (1992) Risk society : towards a new modernity, London, Sage.

BECK, U. (2000) The cosmopolitan perspective: sociology of the second age of modernity. British Journal of Sociology, 51, 79-105.

BECK, U. (2002) The cosmopolitan society and its enemies. Theory, Culture and Society, 19, $17-44$. 
How to cite: Wall, Erika \& Olofsson, Anna. (2008). Young people making sense of risk: How meanings of risk are materialized within the social context of every-day life. Young, 16 (4) 431-448.

BECK, U. (2003) Toward a new critical theory with a cosmopolitan intent. Constellations, 10, 453-468.

BECK, U. (2004) Cosmopolitical realism: on the distinction between cosmopolitanism in philosophy and the social sciences. Global Networks, 4, 131-156.

BECK, U. \& BECK-GERNSHIEM, E. (2001) Individualization, Cambridge, Polity Press.

BECK, U., BONSS, W. \& LAU, C. (2003) The theory of reflexive modernisation. Problematic, hypotheses and research programme. Theory, Culture \& Society, 20, 1-33.

BECK, U., LASH, S. \& GIDDENS, A. (1994) Reflexive modernization : politics, tradition and aesthetics in the modern social order, Oxford, Polity.

DENSCOMBE, M. (2001) Uncertain identities and health-risking behaviour: the case of young people and smoking in late modernity. British Journal of Sociology, 52, 157-177.

FURLONG, A. \& CARTMEL, F. (1997a) Risk and Uncertainty in the Youth Transition. Young: the Nordic Journal of Youth Research, 5, 3-20.

FURLONG, A. \& CARTMEL, F. (1997b) Young people and social change : individualization and risk in late modernity, Buckingham, Open University Press.

GASKELL (2000) Individual and group interviewing. IN BAUER, M. W. \& GASKELL, G. (Eds.) Qualitative research with text, image and sound. London, SAGE.

GIDDENS, A. (1990) Consequences of modernity, Cambridge, Polity Press.

GIDDENS, A. (1991) Modernity and self-identity, Cambridge, Polity Press.

GIDDENS, A. (1994) Living in a post-traditional society. IN BECK, U., LASH, S. \& GIDDENS, A. (Eds.) Reflexive modernization : politics, tradition and aesthetics in the modern social order. Cambridge, Polity Press.

GIDDENS, A. (2002) Runaway World. How Globalisation Is Reshaping Our Lives, London, Profile Books.

GIERYN, T. F. (2000) A Space for Place in Sociology. Annual Review of Sociology, 26, 463496.

GREEN, E., MITCHELL, W. \& BUNTON, R. (2000) Contextualizing risk and danger: An analysis of young people's perceptions of risk. Journal of Youth Studies, 3, 109-126.

HEGGEN, K. (2000) Marginalisation: on the fringe of the periphery - youth as a risky life stage? Young, 8.

LAWY, R. (2002) Risk stories: Youth identities, learning and everyday risk. Journal of Youth Studies, 5, 407-423.

LINDSTROM, B. (1997) A Sense of Place: Housing Selection on Chicago's North Shore. The Sociological Quarterly, 38, 19-39.

LUPTON, D. \& TULLOCH, J. (2001) Border crossings: narratives of movement, 'home' and risk. Sociological Research Online.

LUPTON, D. \& TULLOCH, J. (2002) Risk is part of your life: risk epistemologies among a group of Australians. Sociology 36, 317-334.

MELLOW, M. (2005) The Work of Rural Professionals: Doing the GemeinschaftGesellschaft Gavotte. Rural Sociology, 70, 50-69.

MORGAN, D. (1996) Focus groups. Annual Review of Sociology., 22, 129-152.

MORSE DUNKLEY, C. (2004) Risky geographies: Teens, gender, and rural landscapes in North America. Gender, Place and Culture, 11, 561-579.

NAIRN, K., PANELLI, R. \& MCCORMACK, J. (2003) Destabilizing dualisms. Young people's experiences of rural and urban environments. Childhood, 10, 9-42.

POLLOCK, G. (1997) Individualization and the transition from youth to adulthood. Young: Nordic Journal of Youth Research, 5, 55-68. 
How to cite: Wall, Erika \& Olofsson, Anna. (2008). Young people making sense of risk: How

meanings of risk are materialized within the social context of every-day life. Young, 16 (4) 431-448.

SLOVIC, P., FISCHHOFF, B. \& LICHTENSTEIN, S. (1977) Cognitive processes and social risk taking. IN JUNGERMANN, H. \& DE ZEEUW, G. (Eds.) Decision making and change in human affairs. Dordrecht, Riedel.

SLOVIC, P., FISCHHOFF, B. \& LICHTENSTEIN, S. (1980) Facts and fears: Understanding perceived risk. IN SCHWING, R. C. \& ALBERS, W. A. (Eds.) Societal risk assessment: How safe is safe enough? New York, Plenum Press.

THERBORN, G. (2003) Entangled Modernities. European Journal of Social Theory, 6, 293305.

TULLOCH, J. \& LUPTON, D. (2001) Risk, the mass media and personal biography. Revisiting Beck's 'knowledge, media and information society'. European Journal of Cultural Studies, 4, 5-27.

TURNER (1994) Orientalism, postmodernism, and globalism, London, Routledge.

WEICK, K. E. (1995) Sensemaking in Organizations, Thousand Oaks, Sage.

WIBECK, V. (2002) Genmat i fokus, Linköping, Linköping University. 
How to cite: Wall, Erika \& Olofsson, Anna. (2008). Young people making sense of risk: How meanings of risk are materialized within the social context of every-day life. Young, 16 (4) 431-448.

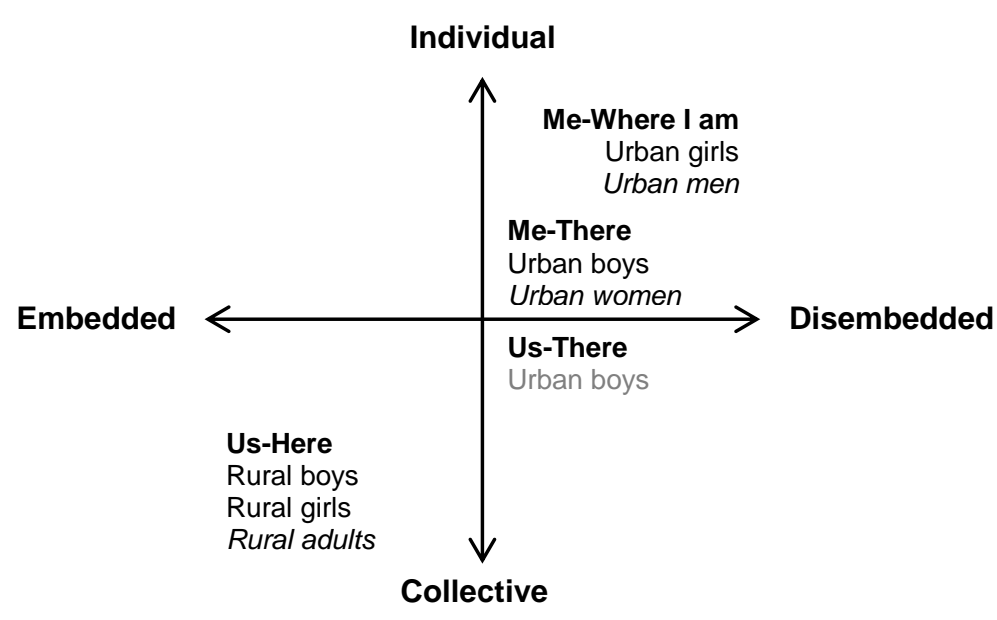

Figure 1. The figure illustrates a theoretical model of sense-making of risk in which the empirical results are shown. 